\title{
Prevalence of Obesity and Abdominal Obesity in Swedish Primary Care and Occupational Health Clinics
}

\author{
Jan Pettersson $^{\mathrm{a}, \mathrm{b}} \quad$ Kari Johansson ${ }^{\mathrm{a}}$ Stephan Rössner ${ }^{\mathrm{a}} \quad$ Martin Neovius $^{\mathrm{a}}$ \\ a Obesity Unit, Karolinska Institutet, Karolinska University Hospital (Huddinge), Stockholm, \\ ${ }^{b}$ Abbott Scandinavia AB, Solna, Sweden
}

Key Words

BMI - Overweight - Sex - Waist circumference

\section{Summary}

Background: The objective of this study was to describe the prevalence of obesity and abdominal obesity in the Swedish primary and occupational health care setting. Patients and Methods: Weight, height, and waist circumference (WC) were measured in 1,583 consecutive patients, aged between $18-65$ years ( $46.4 \pm 12.7$ years), in 39 primary care and occupational health practices in Sweden, in 2006. The National Cholesterol Education Program (NCEP) WC reference values were used to define abdominal obesity $(102$ and $88 \mathrm{~cm}$ for men and women, respectively). Results: The distribution across obesity categories differed significantly between men and women with close to 70 and $55 \%$ of men and women, respectively, having a body mass index (BMI) $\geq 25$. More men than women were overweight (BMI 25-29.9; 45.1 vs. $31.1 \%$ ) and obese (BMI 30-34.9; 19.8 vs. $12.9 \%)$, but less men than women were morbidly obese ( 4.0 vs. $8.9 \%$; $\mathrm{BMI} \geq 35$ ). Increasing prevalence with age was seen until age 60 for both overweight and obesity. More women than men were abdominally obese $(42.5$ vs. $32.7 \%$; $p<0.001$ ). Only 48 and $64 \%$ of the abdominally obese women and men, respectively, had a BMI $\geq 30$. Conclusion: Compared to national Swedish data, the prevalence of overweight and obesity was higher in primary and occupational health care settings. Both morbid obesity and abdominal obesity were highly prevalent and more common in women, implying that awareness of sex differences may be important or that recommended cut-offs are not comparable across sex. Furthermore, a large fraction of the abdominally obese had a $\mathrm{BMI}<$ 30. Both BMI and WC may therefore be important to determine routinely and incorporate into treatment guidelines, in order not to miss patients at risk of obesity-related morbidity.

\section{Introduction}

Overweight and obesity have increased dramatically in Sweden during the last decades in adults, adolescents, and children alike [1-3]. Based on the current National Survey of Living Conditions, approximately 50 and $40 \%$ of adult men and women, respectively, in the general population are now either overweight or obese based on self-reported body mass index (BMI) [4]. Of these, about $10 \%$ are obese in both sexes. Two decades ago, the corresponding figure was only $5 \%$ [5]. Recent cross-sectional population surveys based on measured BMI, however, report a higher prevalence of obesity; in a survey from Southern Sweden, 17 and $16 \%$ of men and women, respectively, were obese [6], and in the MONICA survey from Northern Sweden, the prevalence was even higher with 18 and $19 \%$ of men and women, respectively, being obese [7]. In 18year-old Swedish men, obesity and morbid obesity have increased 5 and 10 times, respectively, between 1969 and 2005 [2]. The composition of the obese category (BMI $\geq 30$ ) has also changed, with BMI $\geq 35$ constituting $13 \%$ in 1969-1974, and $25 \%$ in 2000-2005. However, there is some evidence of a possible stagnation of this trend in children. A recent study of Sjöberg et al. [3] reported that the obesity epidemic may have reached a plateau in urban Swedish boys and possibly reversed among girls. In the US, data from the National Health and Nutrition Examination Survey (NHANES) show that there was no significant increase in the prevalence of obesity over the 4 latest time periods investigated (1999-2000, 2001-2002, 2003-2004, and 2005-2006) for either boys or girls [8]. The prevalence of abdominal obesity in the Swedish general population has been investigated in cross-sectional population surveys. The MONICA survey from Northern Sweden reported in 2004 a prevalence of $16-32 \%$ and $18-55 \%$ for men and women, respectively, in age categories 25-74 years according to the National Cholesterol Education Program (NCEP) cut-offs ( $>102 />88 \mathrm{~cm}$ for men and women, respectively). In

\section{KARGER}

Fax +497614520714

Information@Karger.de

www.karger.com (c) 2008 S. Karger GmbH, Freiburg

Accessible online at:

www.karger.com/ofa 
all age categories, an increased waist circumference (WC) was seen based on the cross-sectional studies conducted between 1990 and 2004 [7].

While the BMI distribution in the general Swedish population is rather well characterized, the prevalence in primary care has until recently been largely unknown [9]. Prevalence estimates of morbid obesity in primary care remain unreported. For planning purposes, it is of interest to know the relationship between the BMI distribution in the general population and the population in primary care. As the population in Sweden, as elsewhere, grows increasingly more obese, it is likely that the burden on primary care will increase disproportionately, since the number of patients with BMI $\geq 35$ appears to increase at a greater rate than of those with BMI 30-34.9 [2,10]. Although costs are positively correlated with BMI from the normal weight range onwards [11-13], the relationship appears to be non-linear, with much greater costs incurred by the morbidly obese [14]. Many of the most obese Swedish patients will even be cared for within the primary health care system, while specialist clinics can only treat a fraction of those cases. The aim of this study was to describe the sex-specific prevalence of overweight, obesity, and morbid obesity in primary and occupational health care in Sweden. Furthermore, the prevalence of abdominal obesity, determined by WC, was estimated.

\section{Patients and Methods}

\section{Patients}

A cross-sectional study design was used to examine BMI in consecutive patients aged 18-65 years consulting a primary care physician, regardless of the reason for the consultation. The study was conducted at 29 primary care and 10 occupational health clinics between October 23 and December 29, 2006. The clinics were recruited from centres of primary care and occupational health from Central and Southern Sweden. Of the 70 clinics invited, 43 accepted the initial invitation, and 39 clinics actually participated. At each centre, a physician chose any 3 days per week during 2 consecutive weeks for inclusion of patients. The instructions were to choose 'typical days at their clinic' in order to exclude days of education, days with many internal meetings, or days when certain subgroups of patients were planned to come to the clinics. A total of 1,614 patients agreed to participate in the study. Overall, 31 data records were excluded due to missing data (no signed report sheet $(n=26)$, missing sex $(n=3)$, missing height or weight $(n=1)$, young age $(15$ years; $n=1))$. The final sample consisted of 1,583 patients. The regional Ethics Committee of Stockholm granted ethical approval. Informed written consent was obtained from each person.

\section{Data Collection}

Physicians or nurses measured weight, height, and WC, and entered the data into a case report form. Weight was measured by the same digital scale (8909 ST Bodyfat, EKS International, Hereford, UK) at all clinics. The measurements were performed with the patients dressed in light clothing without shoes, and $0.6 \mathrm{~kg}$ was subtracted as standard correction for the weight of the remaining clothes. Standing height was measured to the nearest $\mathrm{cm}$ against a wall-mounted stadiometer (Model No: 4444500; Comed Z.A., Strasbourg, France) with the patients' backs against the wall after shoes were taken off. Based on BMI (weight $/$ height ${ }^{2} ; \mathrm{kg} / \mathrm{m}^{2}$ ), patients were classified as underweight $(<18.5)$, normal weight $(18.5-24.9)$, overweight (25-29.9), obese (30-34.9), and morbidly obese ( $\geq 35)$ [15]. According to a recent review conducted by a panel of experts, there is currently no consensus regarding the optimal protocol for measurement of $\mathrm{WC}$, and no scientific rationale has been provided for recommended protocols by leading health authorities [16]. In this study, WC was measured with patients standing dressed in underwear or a light shirt. It was measured at the minimum circumference between the iliac crest and the rib cage. Measurements were taken during the end of a 'relaxed exhale' and rounded to the nearest $\mathrm{cm}$. Based on WC, patients were categorised into 3 categories according to sex-specific cut-offs from NCEP/International Diabetes Federation (IDF) $(<94 /<80 ; 94-102 / 80-88 ;>102 />88$ for men and women, respectively) $[17,18]$.

\section{Statistics}

Statistical analyses were conducted using SPSS, version 15.0 (SPSS Inc., Chicago, IL, USA) and Stata, version 10.0 (Stata, College Station, TX, USA). Descriptive statistics are shown as mean values with standard deviation (SD), and sex differences were assessed by independent samples ttest (age, continuous), one-way ANOVA (with age and sex categories as factors, and continuous BMI/WC/weight/height as the outcome), and chisquare tests (categories of BMI-based obesity and WC-based abdominal obesity). The linear relationship between BMI and WC was assessed by constructing sex-specific multiple linear regression models with $\mathrm{WC}$ as the outcome variable (continuous), and BMI (continuous) and age (continuous) as explanatory variables. Logistic regression was used to investigate potential sex differences in prevalence of overweight, obesity, and morbid obesity. These 3 models were constructed with overweight/obesity/morbid obesity (all dichotomous) as the outcome variable, and sex (male/female), centre (primary care/ occupational health clinic), and age (continuous) as explanatory variables. The categories of BMI-based obesity status $(<18.5$, 18.5-24.9, 25-29.9, 30-34.9, $\geq 35$ ) and WC-based abdominal obesity status (WC $>102 / 88$ for men and women, respectively) were cross-tabulated in order to graphically display the distribution of abdominal obesity across BMI categories. A p value of $<0.05$ was considered statistically significant.

\section{Results}

Patient characteristics are presented in table 1. No significant difference in age between the sexes was detected ( 0.1 years; $\mathrm{p}=0.82)$, while males were heavier $(15 \mathrm{~kg} ; \mathrm{p}<0.001)$, taller (14 cm; $\mathrm{p}<0.001)$, had a higher BMI $\left(0.7 \mathrm{~kg} / \mathrm{m}^{2} ; \mathrm{p}=0.006\right)$, and a greater $\mathrm{WC}(10 \mathrm{~cm} ; \mathrm{p}<0.001)$. BMI, weight, and $\mathrm{WC}$ increased with age in both sexes, although there was no significant difference between the ages from 40 years (BMI and weight) and 50 years (WC). The prevalence of both overweight and obesity increased with age until age 60, but thereafter declined (fig. 1). Differences in patient characteristics in primary care and occupational health are presented in table 2. The patients in occupational health care were older $(2.2$ years; $\mathrm{p}<0.001)$ and taller $(2 \mathrm{~cm} ; \mathrm{p}<0.001)$ compared to those in primary care. Overall and in men, there were no significant differences in either BMI or WC. However, the women in primary care had higher BMI $\left(1 \mathrm{~kg} / \mathrm{m}^{2} ; \mathrm{p}=0.01\right)$ and larger WC $(2.3 \mathrm{~cm} ; \mathrm{p}=0.03)$.

\section{Obesity Status Based on BMI}

The distribution across BMI categories differed significantly between men and women (chi-square $=71.7$; $<<0.001$ ). Less 
Table 1. Patient characteristics in males and females (18-65 years)

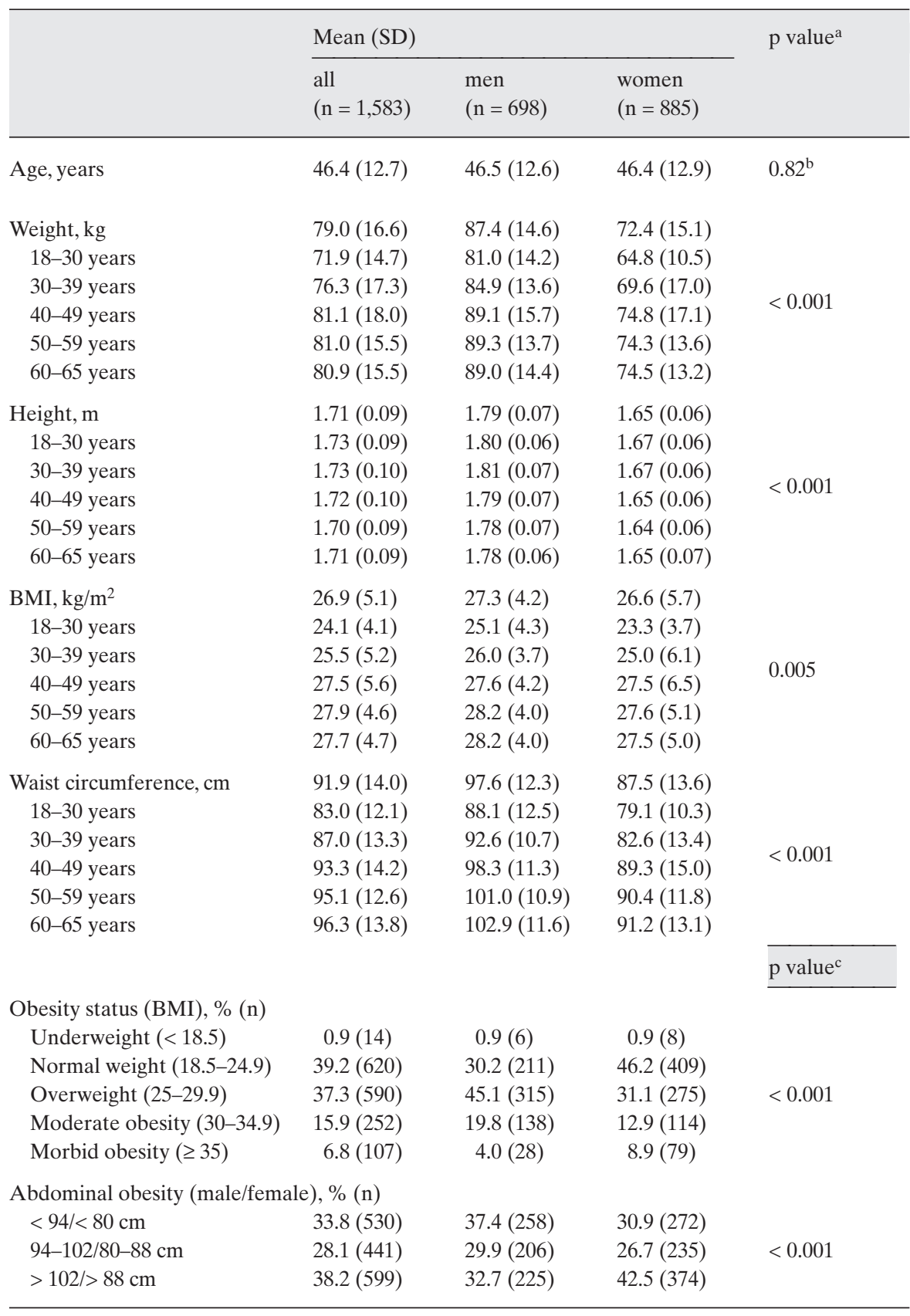

$\mathrm{BMI}=$ Body mass index , categorized according to the WHO definitions [15]; $\mathrm{WC}=$ waist circumference, categorized according to the NCEP/IDF WC categories [17, 18].

${ }^{a}$ Assessed by one-way Anova.

${ }^{\mathrm{b}}$ Assessed by independent samples t-test.

${ }^{\mathrm{c} A s s e s s e d ~ b y ~ c h i-s q u a r e ~ t e s t . ~}$ than $1 \%$ of both males and females were underweight, while 69 and $53 \%$ of men and women, respectively, had a BMI $\geq 25$ (table 1). 24 and $22 \%$ of men and women, respectively, had a $\mathrm{BMI} \geq 30$. In the primary care setting, there were significantly more women compared to the occupational health care clinics who had a BMI $\geq 30,24$ versus $17 \%$ (table 2 ). There were no differences in obesity status between settings for men. After adjustment for age and centre, more men than women were overweight (odds ratio (OR) 2.1; 95\% confidence interval (CI) 1.7-2.6; p $<0.0001$ ), but for morbidly obese patients $(\mathrm{BMI} \geq 35)$, the pattern was the opposite (OR 0.4; 95\% CI $0.3-0.7 ; \mathrm{p}<0.0001)$. No difference was observed for obesity (OR 1.1; 95\% CI 0.9-1.4; $\mathrm{p}=0.30$ ). In men, the morbidly obese constituted $17 \%$ of the obese category, while in women, they constituted $41 \%$. 
Table 2. Patient characteristics stratified by primary care and occupational health care setting

\begin{tabular}{|c|c|c|c|c|c|c|}
\hline & \multicolumn{6}{|l|}{ Mean (SD) } \\
\hline & \multicolumn{2}{|l|}{ all } & \multicolumn{2}{|l|}{ men } & \multicolumn{2}{|l|}{ women } \\
\hline & $\begin{array}{l}\text { primary care } \\
(\mathrm{n}=1,120)\end{array}$ & $\begin{array}{l}\text { occupational } \\
(\mathrm{n}=463)\end{array}$ & $\begin{array}{l}\text { primary care } \\
(\mathrm{n}=471)\end{array}$ & $\begin{array}{l}\text { occupational } \\
(\mathrm{n}=227)\end{array}$ & $\begin{array}{l}\text { primary care } \\
(\mathrm{n}=649)\end{array}$ & $\begin{array}{l}\text { occupational } \\
(\mathrm{n}=236)\end{array}$ \\
\hline Age, years & $45.8(12.9)$ & $48.0(12.2)^{* *}$ & $45.8(12.9)$ & $48.0(11.9)^{*}$ & $45.7(12.9)$ & $48.0(12.5)^{*}$ \\
\hline Weight, kg & $78.8(16.5)$ & $79.6(16.9)$ & $86.9(15.0)$ & $88.6(13.7)$ & $73.0(15.1)$ & $70.9(15.1)$ \\
\hline Height, m & $1.71(0.09)$ & $1.73(0.09)^{* *}$ & $1.79(0.07)$ & $1.80(0.07)^{*}$ & $1.65(0.07)$ & $1.66(0.06)$ \\
\hline BMI, $\mathrm{kg} / \mathrm{m}^{2}$ & $27.0(5.2)$ & $26.6(4.8)$ & $27.2(4.4)$ & $27.4(3.8)$ & $26.8(5.7)$ & $25.8(5.5)^{*}$ \\
\hline Waist circumference, $\mathrm{cm}$ & $91.9(13.9)$ & $92.0(14.2)$ & $97.2(12.5)$ & $98.5(11.7)$ & $88.1(13.6)$ & $85.8(13.5)^{*}$ \\
\hline \multicolumn{7}{|l|}{ Obesity status (BMI), \% (n) } \\
\hline Underweight $(<18.5)$ & $1.0 \%(11)$ & $0.7 \%(3)$ & $1.3 \%(6)$ & $0 \%(0)$ & $0.8 \%(5)$ & $1.3 \%(3)$ \\
\hline Normal weight (18.5-24.9) & $38.6 \%(432)$ & $40.6 \%(188)$ & $31.2 \%(147)$ & $28.2 \%(64)$ & $44.0 \%(285)$ & $52.4 \%(124)$ \\
\hline Overweight (25-29.9) & $36.9 \%(413)$ & $38.3 \%(177)$ & $44.0 \%(207)$ & $47.6 \%(108)$ & $31.7 \%(206)$ & $29.2 \%(69)$ \\
\hline Moderate obesity (30-34.9) & $16.3 \%(183)$ & $14.9 \%(69)$ & $19.3 \%(91)$ & $20.7 \%(47)$ & $14.2 \%(92)$ & $9.3 \%(22)$ \\
\hline Morbid obesity $(\geq 35)$ & $7.2 \%(81)$ & $5.6 \%(26)$ & $4.3 \%(20)$ & $3.5 \%(8)$ & $9.4 \%(61)$ & $7.6 \%(18)$ \\
\hline$p$ value & \multicolumn{2}{|c|}{$N S$} & \multicolumn{2}{|c|}{$N S$} & \multicolumn{2}{|c|}{0.02} \\
\hline \multicolumn{7}{|c|}{ Abdominal obesity (male/female), \% (n) } \\
\hline$<94 /<80 \mathrm{~cm}$ & $33.2 \%(368)$ & $35.2 \%(162)$ & $38.9 \%(180)$ & $34.5 \%(78)$ & $29.1 \%(188)$ & $35.9 \%(84)$ \\
\hline $94-102 / 80-88 \mathrm{~cm}$ & $27.3 \%(303)$ & $30.0 \%(138)$ & $27.9 \%(129)$ & $34.1 \%(77)$ & $26.9 \%(174)$ & $26.1 \%(61)$ \\
\hline$>102 />88 \mathrm{~cm}$ & $39.6 \%(439)$ & $34.8 \%(160)$ & $33.3 \%(154)$ & $31.4 \%(71)$ & $44.1 \%(285)$ & $38.0 \%(89)$ \\
\hline$p$ value & \multicolumn{2}{|c|}{$N S$} & \multicolumn{2}{|c|}{$N S$} & \multicolumn{2}{|c|}{0.05} \\
\hline
\end{tabular}

NS $=$ Not significant.

$* \mathrm{p}<0.05$.

$* * \mathrm{p}<0.001$

\section{Abdominal Obesity Status Based on Waist Circumference}

The prevalence of abdominal obesity was 43 and $33 \%$ in women and men, respectively, according to NCEP cut-offs (table 1). The distribution of abdominal obesity across BMI categories is shown in figure 2. Although increasing BMI was associated with increasing prevalence of abdominal obesity, a large number of patients were abdominally obese but had a $\mathrm{BMI}<30(36 \%$ of men and $52 \%$ of women). BMI and WC were highly correlated (fig. 3), and the variations in BMI, adjusted for age, explained 76 and $79 \%$ of the variation in WC in females and males, respectively. Each 1 unit of BMI increase was associated with an increase in WC by 2.0 and $2.4 \mathrm{~cm}$ in women and men, respectively. While the point estimate of the prevalence of BMI-based obesity was greater for men than women, men were significantly less likely to be abdominally obese (OR 0.6; 95\% CI 0.5-0.8; p 0.0001) (table 1).

\section{Discussion}

We investigated the prevalence of obesity and abdominal obesity in primary and occupational health care in Sweden. The obese fraction in this setting was higher compared to both national surveys of self-reported BMI [19] and surveys of mea- sured BMI in the general population [6,7]. In addition, almost every 10th woman was morbidly obese, making it twice as common as in men. The prevalence of abdominal obesity was 43 and $33 \%$ in women and men, respectively, but only 48 and $64 \%$ of these were obese defined by BMI. This indicates a high likelihood of underdiagnosis of individuals at risk unless $\mathrm{WC}$ is measured in parallel, provided that the reference values for WC are good predictors of metabolic risk.

As obesity increases, so does the risk of many common conditions seen by primary care physicians, such as musculoskeletal disorders, hypertension, type 2 diabetes, dyslipidaemia, and skin problems $[15,20]$. Hence, it is not surprising that the prevalence of obesity is higher in primary care than in the general population, and this has been documented previously in both Swedish and international studies [9, 21, 22]. The magnitude was also large, with 22 and $25 \%$ of women and men, respectively, having a BMI $\geq 30$ compared to approximately $10 \%$ in both sexes in the general population, based on self-reports [23]. Higher prevalence has been reported based on measured BMI data from Gothenburg in 2002 (15\% for men and $11 \%$ for women) and Northern Sweden (MONICA; $19 \%$ for men and $18 \%$ for women, in 2004). There are, however, large variations in prevalence between urban and rural areas in Sweden [24], so a greater prevalence is expected in Northern Sweden. 


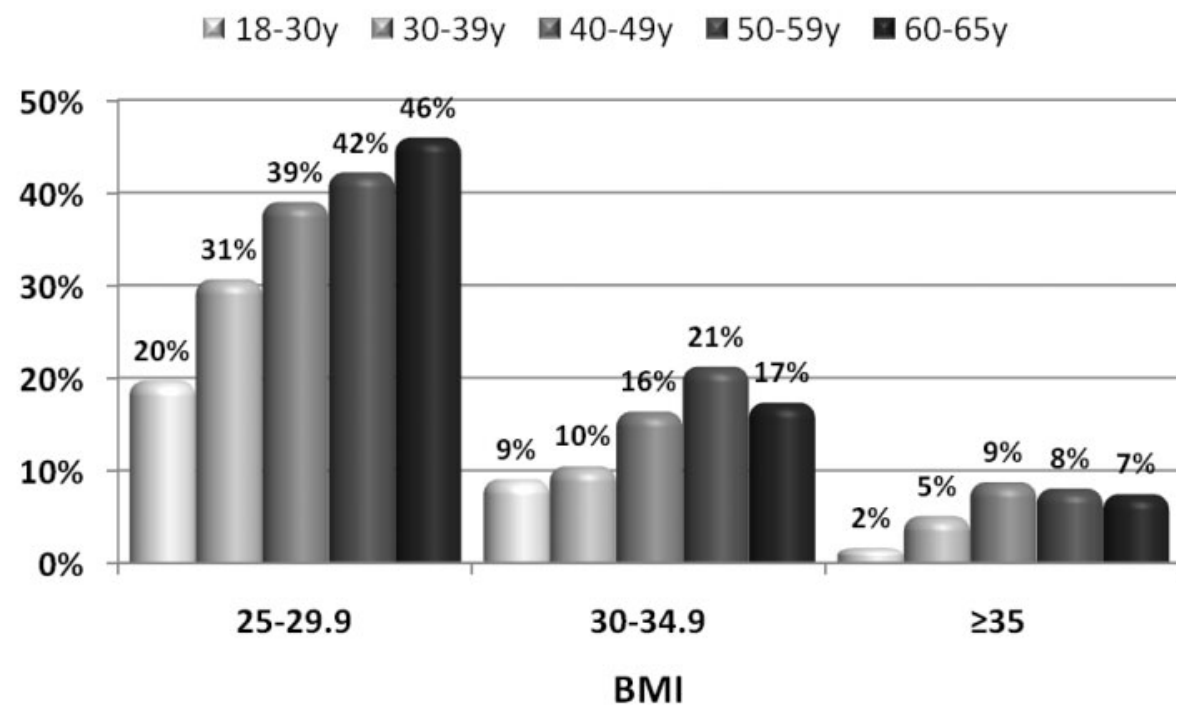

Fig. 2. Distribution of abdominal obesity across categories of BMI in males $(n=698)$ and females $(\mathrm{n}=885)$. Abdominal obesity defined according to the NCEP definition (waist circumference in women $>88 \mathrm{~cm}$; and in men $>102 \mathrm{~cm}$ [17]).
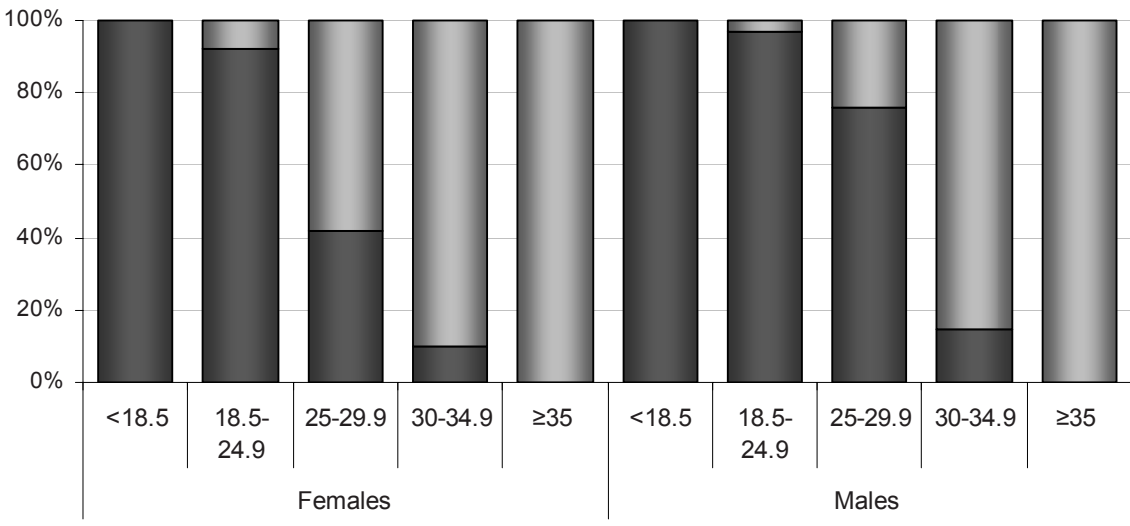

$\square$ Not Abdominally Obese $\square$ Abdominally Obese

This study confirms some of the findings regarding prevalence and sex differences of the recently published Swedish arm of the IDEA study, including 2,077 primary care patients [9]. The prevalence of abdominal obesity there and in the present study was similar for men (30.8 vs. $32.7 \%$ ) and women $(40.7$ vs. $42.5 \%)$. Although the prevalence of obesity was also similar (men 20.2 vs. $23.8 \%$; women 19.8 vs. $21.8 \%$ ), the IDEA study did not report morbid obesity. Furthermore, the age group investigated differed slightly, with the present study only including patients aged 18-65 years compared to 18-80 years in the IDEA study. In both the current study and the IDEA study, more men were overweight and obese, as judged by BMI, while more women than men exceeded the cut-offs for abdominal obesity. Classically, male and female obesity have been described as 'apple-shaped/android' and 'pearshaped/gluteo-femoral,' respectively. In both studies, a higher prevalence of abdominal obesity was found in Swedish women than in men. This may reflect greater problems with central fatness in women, or that the published reference values for
WC are inappropriate for Swedish women and/or men. The scientific basis for the WC cut-offs can be questioned, as they were derived from the average values corresponding to BMI 30 [25], and not from prospective studies of morbidity or mortality. Also, similarly to BMI, they are not age-, sex- or ethnicity-specific. Hence the findings of women having greater prevalence of abdominal obesity in this and other studies [9, $21,22]$ may be an indication of inappropriate cut-offs rather than poorer metabolic health in women.

While the rates of overweight and obesity were higher in men than in women, morbid obesity was significantly higher in women, and the magnitude was alarming. To the best of our knowledge, the prevalence of morbid obesity in the Swedish primary care setting has not been described previously. Of all women with $\mathrm{BMI} \geq 30,41 \%$ had a $\mathrm{BMI} \geq 35$. For men, the corresponding percentage was $16 \%$. In a population-based study of Swedish 18-year-old men, it has recently been described that the percentage of the morbidly obese in the obese category increased from $13 \%$ in $1969-1974$ to $25 \%$ in $2000-2005$ [2]. 

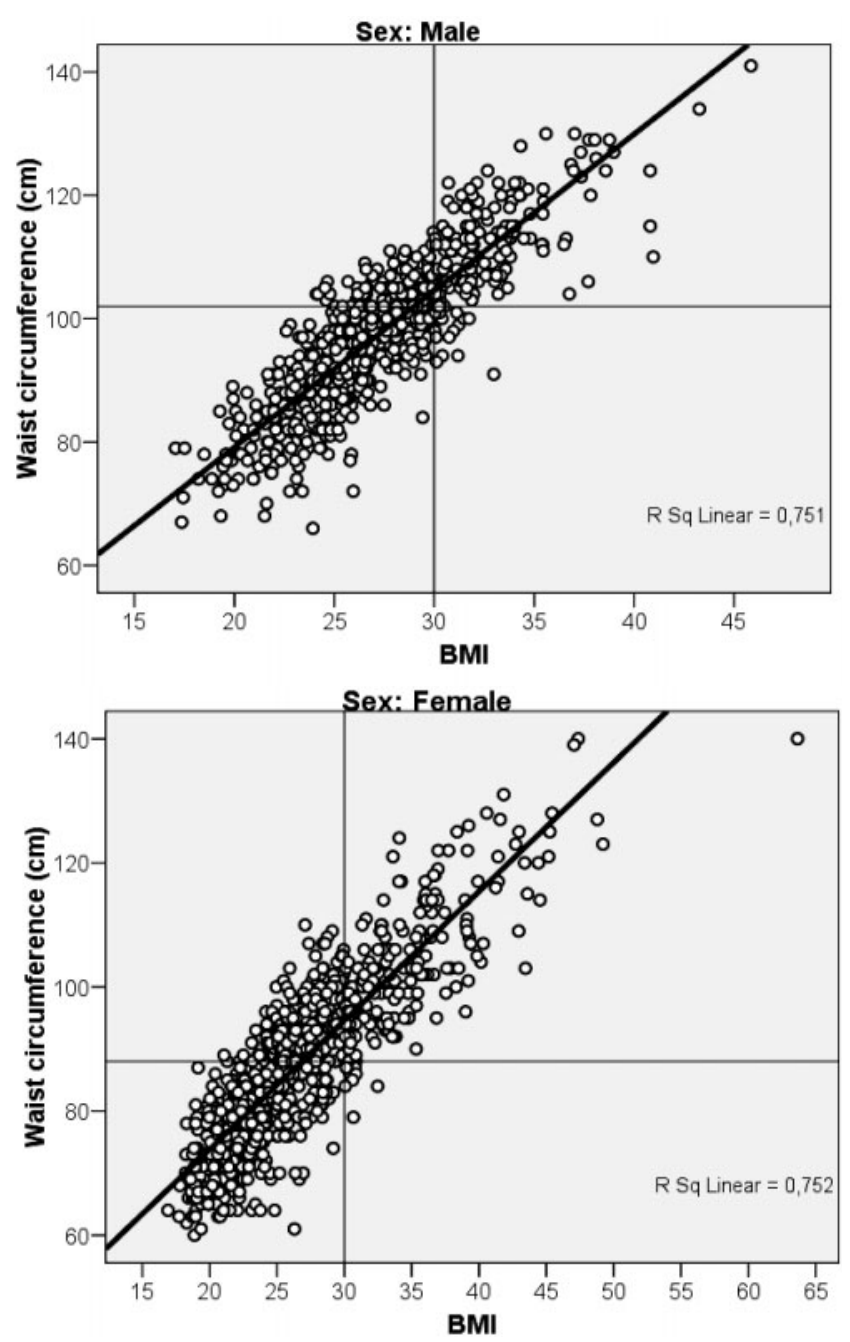

Fig. 3. Association between BMI and waist circumference in males $(\mathrm{n}=$ $698)$ and females $(\mathrm{n}=885)$. Reference lines denote the cut-offs for obesity (based on BMI) and abdominal obesity (according to the NCEP definition [17])

Similar data have been reported for US adults [10]. In that perspective, the percentage of morbidly obese men as a share of all obese seems low in primary care, while for women the percentage is alarmingly high. Unfortunately, no comparative data for morbid obesity are available from the general population for adults, and some caution is warranted due to the relatively low subgroup sample size (28 men and 79 women). To the best of our knowledge, the only data available for morbid obesity is from a study based on measured BMI in Southern Sweden (2001-2003), reporting a prevalence of 3 and $9 \%$ for men and women, respectively [6].

In primary and occupational health care, often only weight and height are measured, and BMI hopefully calculated. Although there was a strong correlation between BMI and WC, only a small fraction of the abdominally obese was detected if BMI was used as a screening tool for persons at risk. In fact, only a third of the abdominally obese women and a little more than half of the men were also obese based on BMI. As quali- fication for behavioural modification and/or pharmaceuti$\mathrm{cal} /$ surgical treatment as well as referral to secondary and tertiary care is often based on BMI alone, many abdominally obese patients may be missed if WC is not measured as well. In Sweden, for example, pharmacotherapy is only reimbursed for obese patients with $\mathrm{BMI} \geq 35$, or BMI $\geq 28$ with type 2 diabetes or dyslipidaemia [26]. Similarly, obesity surgery in Sweden is recommended from $\mathrm{BMI} \geq 35$ [27]. No consideration of abdominal obesity is made explicit in the guidelines for either pharmaceutical or surgical interventions.

Based on the current trends, it is likely that the pressure on primary care from obesity will increase. During the last decades, overweight and obesity have increased not only in adults, but also in young children and adolescents [1]. Some data point towards a stabilisation of the prevalence in children [3], but the absolute levels remain high. Overweight adolescents generally become overweight and later obese adults [28, 29]. As many obesity-related diseases do not start to exert their toll until mid-life, there is a considerable delay before the full impact on primary care is realised. As the prevalence of obesity quadrupled in 10-year-old Swedish children during the last 20 years [30], and quintupled in adolescent males over the last 35 years [24], the pressure is likely to increase markedly.

The strengths of this study were its at least reasonable representativeness for Swedish primary and occupational health care, measured height, weight, and WC instead of self-reported data, and sufficient sample size for stratified analyses regarding sex differences in obesity and abdominal obesity. It is possible that a certain degree of selection bias resulted due to patients' right to decline participation, if this decision was influenced by obesity status and not random. It is known that non-participation tends to increase with increasing obesity [31], and is likely to result in an underestimate of the actual prevalence. This bias is present in the majority of prevalence studies on obesity, as individuals seldom can be forced to participate, and we could not address it in the present study. The lack of more detailed measures of body composition as well as blood samples preclude more detailed analyses of the relationship between the proxy measures used and more direct measures of cardiovascular risk. Finally, the inclusion of both occupational and primary care practices may result in some distortion, as it is known that people who work generally have better health status than those who do not ('healthy worker effect'). We found no significant differences in men, while women in primary care had both higher BMI and WC than in occupational health clinics.

In summary, we confirmed previous findings of a higher prevalence of obesity in primary care than in the general population, as well as sex differences regarding general and abdominal obesity. We extended previous findings by reporting an alarmingly high prevalence of morbid obesity in women, and also by showing how approximately $50 \%$ of abdominally obese adults are missed if using BMI-based obesity as a selec- 
tion criterion for obesity-directed medical care. It may therefore be suitable to routinely measure both BMI and WC, and incorporate $\mathrm{WC}$ into treatment decision algorithms alongside BMI.

\section{Supplementary Material}

Additional material is available online via $w w w . k a r g e r . c o m / o f a$.

\section{Sources of Support}

This study was funded by Abbott Scandinavia.

\section{Potential Conflicts of Interest}

JP is employed as a Medical Advisor at Abbott. SR has received honoraria and acted as an advisor for Abbott, Roche, and Sanofi-Aventis. MN has acted as a consultant for Abbott and Sanofi-Aventis.

\section{References}

1 Neovius M, Janson A, Rossner S: Prevalence of obesity in Sweden. Obes Rev 2006;7:1-3.

2 Neovius M, Teixeira-Pinto A, Rasmussen F: Shift in the composition of obesity in young adult men in Sweden over a third of a century. Int $\mathrm{J}$ Obes (Lond) 2008;32:832-6.

3 Sjoberg A, Lissner L, Albertsson-Wikland K, Marild S: Recent anthropometric trends among Swedish school children: evidence for decreasing prevalence of overweight in girls. Acta Paediatr 2008;97:118-23.

4 Sundquist K, Qvist J, Johansson SE, Sundquist J: Increasing trends of obesity in Sweden between 1996/97 and 2000/01. Int J Obes Relat Metab Disord 2004;28:254-61.

5 Lissner L, Johansson SE, Qvist J, Rossner S, Wolk A: Social mapping of the obesity epidemic in Sweden. Int J Obes (Lond) 2000;24:801-5.

6 Nyholm M, Gullberg B, Merlo J, Lundqvist-Persson C, Rastam L, Lindblad U: The validity of obesity based on self-reported weight and height: implications for population studies. Obesity (Silver Spring) 2007;15:197-208.

7 Lilja M, Eliasson M, Stegmayr B, Olsson T, Soderberg S: Trends in obesity and its distribution: data from the Northern Sweden MONICA Survey, 1986-2004. Obesity (Silver Spring) 2008;16:1120-8.

8 Ogden CL, Carroll MD, Flegal KM: High body mass index for age among US children and adolescents, 2003-2006. JAMA 2008;299:2401-5.

9 Sjoholm A: [Strong connection between abdominal obesity and socioeconomic factors. 'Swedish' IDEA study shows relation to cardiovascular diseases] Lakartidningen 2007;104:3862-6.

10 Sturm R: Increases in morbid obesity in the USA 2000-2005. Public Health 2007;121:492-6.

11 Finkelstein EA, Fiebelkorn IC, Wang G: National medical spending attributable to overweight and obesity: how much, and who's paying? Health Aff (Millwood) 2003;Suppl Web Exclusives:W3219-26.

12 Quesenberry CP Jr, Caan B, Jacobson A: Obesity, health services use, and health care costs among members of a health maintenance organization Arch Intern Med 1998;158:466-72.
13 Sturm R: The effects of obesity, smoking, and drinking on medical problems and costs. Obesity outranks both smoking and drinking in its deleterious effects on health and health costs. Health Aff (Millwood) 2002;21:245-53.

14 Andreyeva T, Sturm R, Ringel JS: Moderate and severe obesity have large differences in health care costs. Obes Res 2004;12:1936-43.

15 World Health Organisation: Obesity: preventing and managing the global epidemic. Report of a WHO consultation. World Health Organ Tech Rep Ser 2000;894:i-xii, 1-253.

16 Ross R, Berentzen T, Bradshaw AJ, Janssen I, Kahn HS, Katzmarzyk PT, Kuk JL, Seidell JC, Snijder MB, Sorensen TI, Despres JP: Does the relationship between waist circumference, morbidity and mortality depend on measurement protocol for waist circumference? Obes Rev 2008;9:312-25.

17 Third Report of the National Cholesterol Education Program (NCEP) Expert Panel on Detection, Evaluation, and Treatment of High Blood Cholesterol in Adults (Adult Treatment Panel III) final report. Circulation 2002;106:3143-421.

18 Alberti KG, Zimmet P, Shaw J: The metabolic syndrome - a new worldwide definition. Lancet 2005; 366:1059-62.

19 Persson G, Danielsson M, Rosen M, Alexanderson K, Lundberg O, Lundgren B, Stenbeck M, Wall S: Health in Sweden: the National Public Health Report 2005. Scand J Public Health Suppl 2006;67: 3-10.

20 Field AE, Coakley EH, Must A, Spadano JL, Laird N, Dietz WH, Rimm E, Colditz GA: Impact of overweight on the risk of developing common chronic diseases during a 10-year period. Arch Intern Med 2001;161:1581-6.

21 Balkau B, Deanfield JE, Despres JP, Bassand JP, Fox KA, Smith SC Jr, Barter P, Tan CE, Van Gaal L, Wittchen HU, Massien C, Haffner SM: International Day for the Evaluation of Abdominal Obesity (IDEA): a study of waist circumference, cardiovascular disease, and diabetes mellitus in 168,000 primary care patients in 63 countries. Circulation 2007;116:1942-51.
22 Hauner H, Bramlage P, Losch C, SteinhagenThiessen E, Schunkert H, Wasem J, Jockel KH, Moebus S: Prevalence of obesity in primary care using different anthropometric measures - Results of the German Metabolic and Cardiovascular Risk Project (GEMCAS). BMC Public Health 2008;8: 282.

23 Persson L: Every tenth Swede is obese (In Swedish Var fjärde svensk är fet). Välfärd 2007;1:8-9.

24 Neovius M, Rasmussen F: Place of residence and obesity in 1,578,694 young Swedish men between 1969 and 2005. Obesity (Silver Spring) 2008;16: 671-6.

25 Lean ME, Han TS, Morrison CE: Waist circumference as a measure for indicating need for weight management. BMJ 1995;311:158-61.

26 Läkemedelsförmånsnämnden (cited 2008-02-28) available from $w w w . l f n . s e /$.

27 Svensk förening för övre abdominell kirurgi (cited 2008-02-24); available from www.sfoak.se/ riktlinjerrapporter/.

28 Guo SS, Roche AF, Chumlea WC, Gardner JD Siervogel RM: The predictive value of childhood body mass index values for overweight at age $35 \mathrm{y}$. Am J Clin Nutr 1994:59:810-9.

29 Guo SS, Wu W, Chumlea WC, Roche AF: Predicting overweight and obesity in adulthood from body mass index values in childhood and adolescence. Am J Clin Nutr 2002;76:653-8.

30 Marild S, Bondestam M, Bergstrom R, Ehnberg S, Hollsing A, Albertsson-Wikland K: Prevalence trends of obesity and overweight among 10-yearold children in western Sweden and relationship with parental body mass index. Acta Paediatr 2004; 93:1588-95.

31 Nyholm M, Gullberg B, Rastam L, Lindblad U: What is the accurate prevalence of obesity in Sweden in the 21st century? Methodological experiences from the skaraborg project. Obesity (Silver Spring) 2008;16:896-8. 